\title{
PAEDIATRIC DIAGNOSTIC TONSILLECTOMY: A REVIEW OF OUR PRACTICE
}

HUW JONES ${ }^{1}$, SUNIL SHARMA ${ }^{1}$, SUJATA DE ${ }^{1}$.

${ }^{1}$ DEPARTMENT OF PAEDIATRIC ENT SURGERY, ALDER HEY CHILDREN'S NHS FOUNDATION TRUST, LIVERPOOL, UNITED KINGDOM.

\section{Conclusions: Tonsillar lymphoma generally presents with rapid tonsillar enlargement with B symptoms. With an unreliable grading system we believe asymmetrical tonsils in isolation, existing for over 6 weeks does not warrant tonsillectomy.}

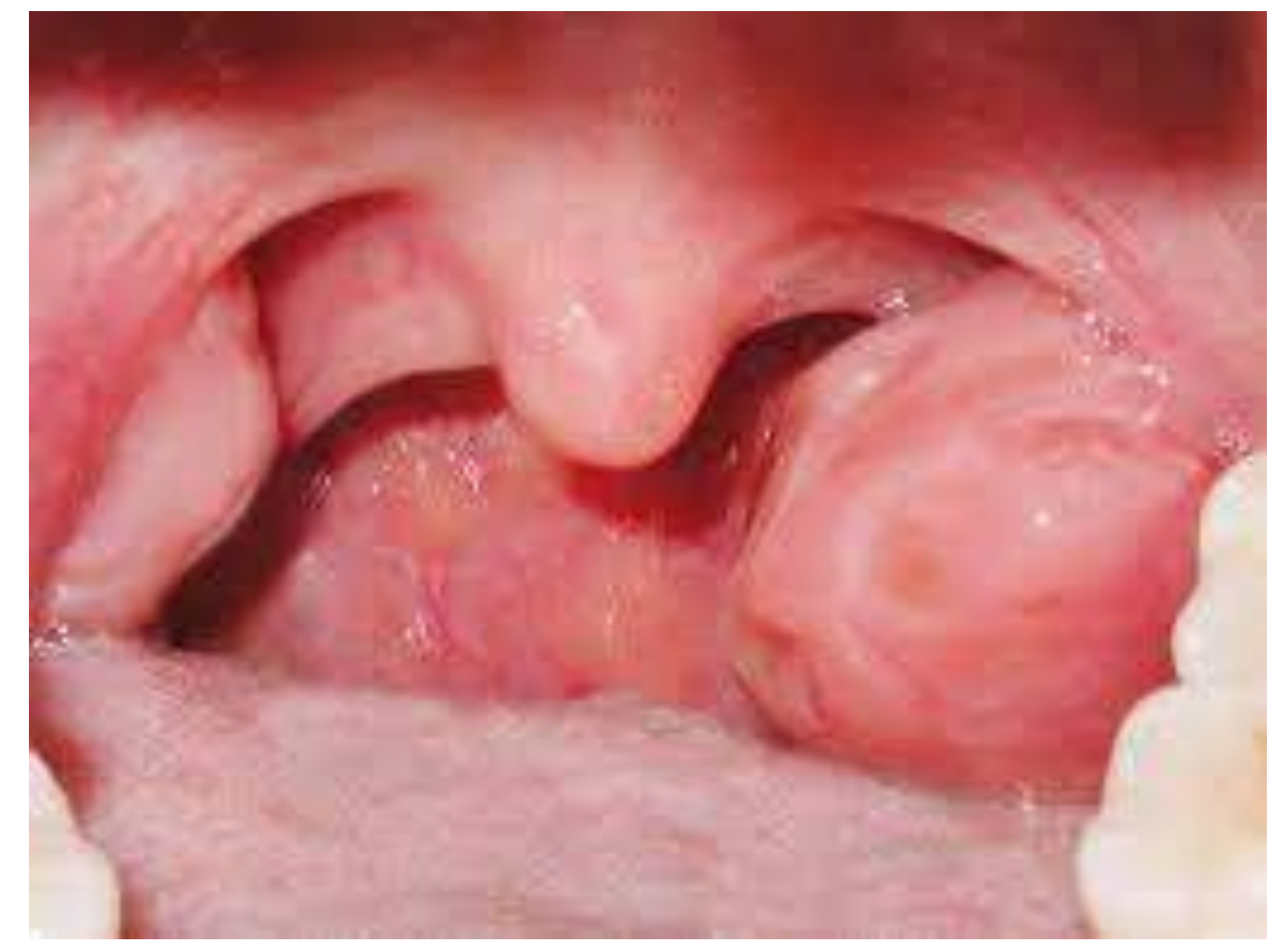

\begin{abstract}
OBJECTIVES
Diagnostic tonsillectomy is performed to exclude malignancy. It is associated with a post-operative hemorrhage rate of $3.5 \%$, which is more dangerous in small children. No previous case series for asymmetrical tonsils have detected tonsil lymphoma. We wanted to review our local diagnostic tonsillectomy practice.
\end{abstract}

\section{METHODS}

Retrospective review of clinical notes and histopathological reports for all diagnostic tonsillectomies from June 2013 to June 2016 at Alder Hey Children's Hospital.

RESULTS

We recorded data for 168 patients. Bilateral tonsillectomies accounted for 152 operations (90.5\%). Lymphoid hyperplasia accounted for $95 \%$ of histological diagnosis with no malignancies found. Pre-operative tonsil grading demonstrated no statistically significant association with histological tonsil weight difference (ANOVA $p=0.10$ ). Actinomycosis had little affect on tonsil weight difference when we compared patients with bilateral actinomycosis and no actinomycosis ( $t$-test $p=0.540$ ) and between tonsils in patients with unilateral tonsil colonisation (paired t-test $\mathrm{p}=0.448$ ). Recurrent tonsillitis was more prevalent in patients with actinomycosis than OSA/sleep disordered breathing (39\% vs $15 \%$ ). A literature search yielded five smaller case series of palatine tonsil asymmetry in children with no malignancy found. Case-control studies report tonsillar asymmetry as the most common presenting symptom $(73 \%)$ in tonsillar lymphoma. This enlargement usually occurs rapidly within 6 weeks with new obstructive or systemic B-type symptoms. A Turkish epidemiological study found asymmetrical tonsils in $1.7 \%$ of the healthy paediatric population. We therefore estimate there to be over 210,000 children with asymmetrical tonsils in the UK.

\section{Corresponding author:}

Sunil Sharma

Department of Paediatric ENT Surgery, Alder Hey Children's Hospital, Eaton Road, Liverpool. L12 2AP.

Email: sunilsharma@doctors.org.uk 